\title{
Research on Battery's charging system based on the Fuzzy control
}

\author{
Wang Fu-shun \\ College of Information Science \& Technology \\ Hebei Agricultural University \\ HeBei Baoding, China \\ wangfushun@yahoo.cn
}

\author{
Suo Xue-song \\ College of mechanical \& electrical engineering \\ Hebei Agricultural University \\ HeBei Baoding, China \\ 707412641@qq.com
}

\begin{abstract}
Based on J. A. Mas 's law and the characteristics of lead-acid battery charging, provided a intelligent and dynamic Charging ideal with a fuzzy control ideal. Experiments show: The systems based on fuzzy control enable the charging current to achieve real-time changes according to the acceptable current size of the battery, enhanced the energy efficiency and avoid over-charge and less-charge effectively, realized efficient, fast and safe charging.
\end{abstract}

Keywords-storage battery; fuzzy control; intelligent charge; dynamic charge

\section{INTRODUCTION}

Lead-acid battery were widely used in electric cars, uninterrupted power supply owe to the manufacturing cost low, large capacity, low prices, mature technology, etc. The battery charge and discharge is a complex electrochemical process, and the traditional charging technology mode more used constant pressure, constant pressure and current limit, constant flow, can't follow the internal battery physical chemistry rule, not control charging real-time, lack of adaptive ability, so, battery time is long, has overcharge, owe charge, chromatography, gas battery overheat and so many faults. According to the survey, The lead-acid battery service life generally in $3 \sim 5$ years, far less than $10 \sim 15$ years of its design life, cause the battery waste and environmental pollution. Therefore, how to realize the faster and more efficient nondestructive charging has been got widely attention in battery application field.

\section{THE EVOLUTION OF CHARGING MODE}

Batteries have been one hundred years of history; its charge control mode had been constantly development. A currently used charging method is three-stage charging, The model can achieve simply and low cost, can satisfy the basic battery requirements. But to achieve short time and high capacity charging, have to improve the constant voltage value. So, can cause charge voltage higher than the plate oxygen evolution voltage and produce oxygen evolution. In addition, easy to cause water loss and interior high temperature of battery during charging, form thermal runaway and damage the battery, can't solve vulcanization failure because the battery long-term shelved.

Take the MAS LAW as theories foundation, based on acceptable best charging electric current curve, and designed a fuzzy control, intelligent, dynamic charging system. Take PIC6014 microcontroller as control core, using the fuzzy control theory to control charge process intelligently, using pulse charging ways, online real-time detection for charging status, make the actual charge curve better follow the ideal charge curve, has achieved the good effect of charging, realized the efficient, quick and safe charge.

\section{FAST CHARGING PRINCIPLE}

During charging, if can percept the accept ability of battery, the proper charging electric current can get, and the efficient, fast, and intact charging will be realized.

\section{A. Electrochemical theory basis}

When charging began, the rise of battery voltage is mainly by the battery internal ohms pressure drop, followed by concentration polarization. But when charge to near the gas evolution voltage, strong concentration polarization increased rapidly, ohms pressure drop and electrochemical polarization changed little, then concentration polarization in the battery voltage rising play a decisive role.Fig. 1 illustrates the relationship between consumption in that part of the polarization current and the state of charge in the conventional charging process, it clear that as the charging and charge current increasing, this kind of electrochemical polarization more significant.

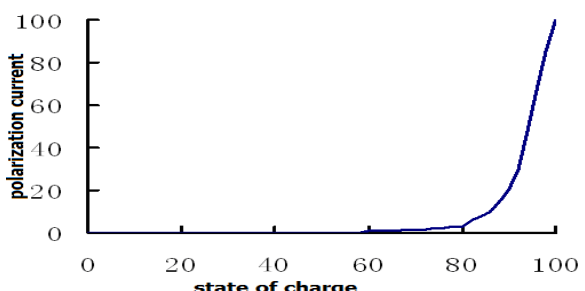

Fig.1 Relationship between polarization current and state of charge

\section{B. Brief introduction of Mas law}

In the research of the maximum acceptable charge current, American scientists j. a. Mas find out the reasons and law of gas evolution in the fast charging process, and forward the acceptable charge current curve with the premise of the lowest rate of gas evolution, as shown in fig. 2: during charging, the acceptable current was decreased exponentially with the increase of charging time.

$$
I=I_{0} e^{-\alpha t}
$$

I: acceptable charging current;

$\mathrm{I}_{0}$ : the max charging current at $\mathrm{t}=0$, it was decided by the state of battery;

$\alpha$ : decay constant, charging acceptance ratio. 


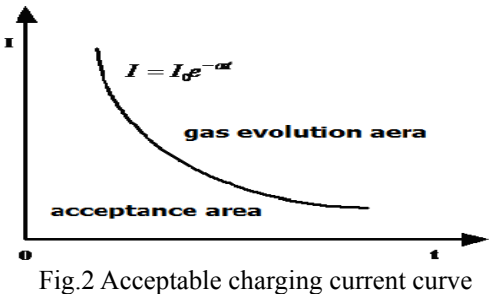

Base on the right moving continuously segmented Mas-curve, the intelligent charging system had looked for one charging current which can make full use of active substances and do not produce gas evolution at every moment, namely got real-time acceptable charging current in the whole charging process.

\section{SYSTEM HARDWARE DESIGN}

\section{A. Master control unit}

Microcomputer pic6014 as core of control circuit, through collection of terminal voltage, charging current and battery's temperature signals, analysis ,fuzzy reasoning, fuzzy decision process, and aim to control the charging current. System structure was shown as fig. 3.

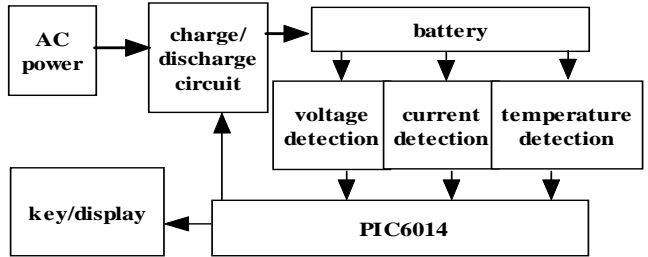

Fig. 3 system structure diagram

\section{B. Buck/Boost charging and discharging circuit}

Charging device used AC-DC-DC transform circuit, As shown in Fig. 4. Through the rectifier transformer, AC-DC section exchanged AC power supply to the DC voltage, that's U1. DC-DC part adopts Buck/Boost circuit.
Buck/Boost circuit means that a direction for Buck circuit charges to battery; the other direction for Boost circuit, that discharge from battery.

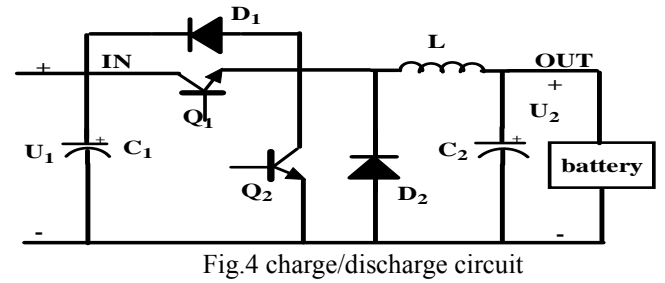

\section{CONTROL STRATEGY ANALYSIS}

The actual charge current curve is influenced by surroundings temperature, the battery's discharge depth, and the capacity and load current changes. It's non linear and time-varying system. So it's hard to find the accurate mathematical model to describes the characteristic curves, the most effective way is to applicant the fuzzy control, based on the knowledge of the expert and experience to establish fuzzy control rules, through the fuzzy logic reasoning complete control decision-making process, and to realize the adjust control of object.

The fuzzy controller composed by three main function modules, fuzzy module, fuzzy reasoning module, image clearness module. The core of the fuzzy controller is fuzzy reasoning and rule base which contains language.

\section{A. Inputs and outputs}

The fuzzy controller adopt with double inputs and single output model, input 1: $\Delta \mathrm{u} / \Delta \mathrm{t}$ is change rate of twice adjacent sample of sampling voltage; Input 2: $\Delta \mathrm{T} / \Delta \mathrm{T}$ is alteration ratio of battery temperature, $\Delta \mathrm{t}$ is the sampling period; Output: the voltage controller UK, it can control charging current by the main circuit, fig. 5 displayed the intelligent charging device's fuzzy control function.

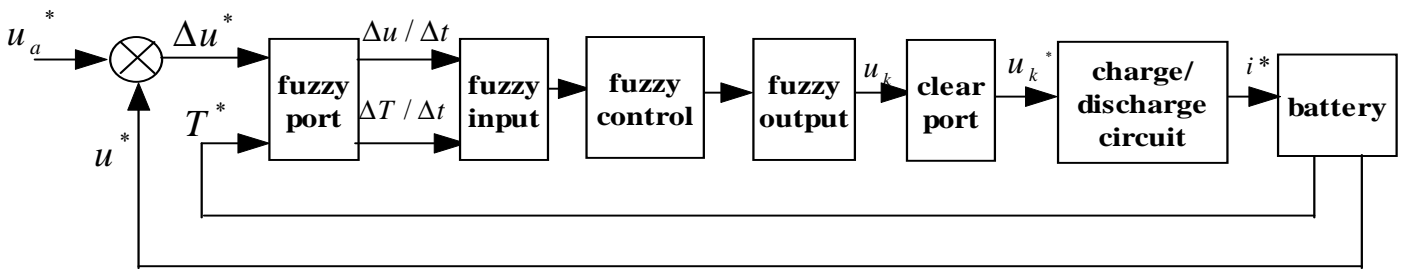

Fig.5 fuzzy control design diagram of intelligent charge device

\section{B. Fuzzy processes}

Fuzzy process converts accurate quantity into fuzzy amount. The specific processes need to quantify, fuzzy partition and fuzzy expression. Quantitative essence is continuous precise value's discrimination. Fuzzy partition is to the domain range fix the number of fuzzy. Fuzzy expression is to define fuzzy quantity's membership functions.

During charging, the temperature is always on the rise stage, so for the $\Delta \mathrm{T} / \Delta \mathrm{t}$ can be divided into five fuzzy state: VS (very small), S (small), M (middle), L (big), VL (very large). The corresponding fuzzy domain $\{1,2,3,4,5,6,7,8,9\}$ is temperature change value, it to say the temperature rise one unit, twice units...,ninth units. one unit represents change $0.1{ }^{\circ} \mathrm{C}$ in one time unit, one time unit is $400 \mathrm{~ms}$ (can be changed according to specific requirements). Fig. 6 showed the membership functions of $\Delta \mathrm{T} / \Delta \mathrm{t}$.

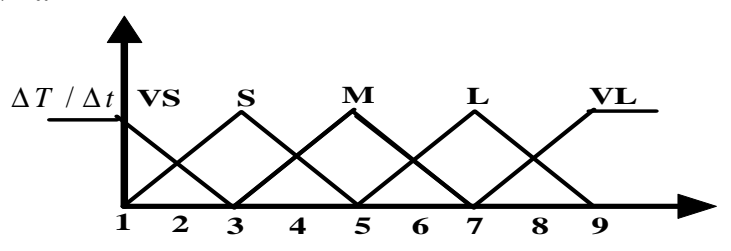

Fig.6 Membership function curve of $\Delta \mathrm{T} / \Delta \mathrm{t}$

For the input $\Delta \mathrm{u} / \Delta \mathrm{t}$, in the battery terminal voltage's 
change curve, the max change rate happen at the charging forepart and before the termination. the Input $\Delta \mathrm{u} / \Delta \mathrm{t}$ and output $u$ all choose NB, NM, ZE, PM, PB as language variables, the membership functions of quantitative domain $\{3,2,1,0,1,2,3\}$ as shown in Fig. 7 .

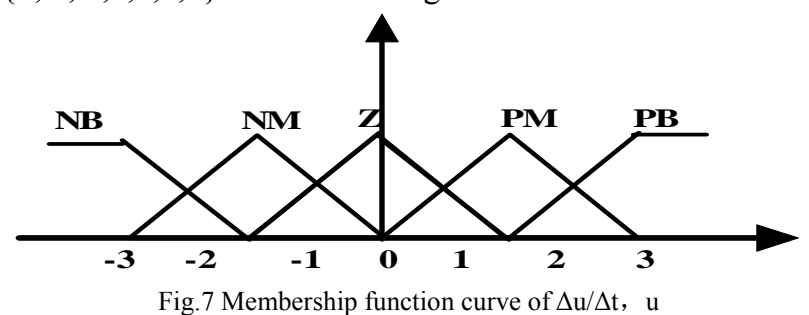

\section{Fuzzy reasoning}

Fuzzy reasoning makes fuzzy relation which corresponding with language variables in the control rules' before and after to do fuzzy operation. Control rules are core of fuzzy controller, need technicians to revise through experiment and rely on experience continually and finally determined the best scheme. By test data and experience value can be shown in table 1 , namely the fuzzy control rule table.

TABLE I . FUZZY CONTROL RULE TABLE

\begin{tabular}{|c|c|c|c|c|c|}
\hline \multirow{2}{*}{$\Delta u / \Delta t$} & \multicolumn{5}{|c|}{$\Delta T / \Delta t$} \\
\cline { 2 - 6 } & VS & S & M & L & VL \\
\hline PB & OVL & OVL & OL & OL & OM \\
\hline PM & OVL & OL & OL & OM & OM \\
\hline Z & OL & OL & OM & OS & OS \\
\hline NM & OL & OM & OM & OM & OVS \\
\hline NB & OM & OS & OS & OVS & OVS \\
\hline
\end{tabular}

According to input/output relationship in the fuzzy input and rule library, the output fuzzy controller UK can be got, the flow:

$$
\mathrm{u}_{\mathrm{k}}=\left(\mathrm{T}^{*} \times \Delta \mathrm{u}^{*}\right) \cdot \mathrm{R}
$$

$\mathrm{R}$ : fuzzy relations in rule library.

\section{Algorithms for clearness}

In order to control the controlled object, need convert the output into accurate value, this process was called clearness. The fuzzy output value $i^{*}$ is the fuzzy subset in the output domain, only transfer it into accurate control quantity can force to object. Clearness method has three kinds: maximum membership degree, weighted average method and the median method. Here, use the weighted average method, it can use in formations provided by fuzzy subsets accurately, and the calculation formula:

$$
U_{K}^{*}=\left[\sum_{i} u_{k\left(u_{i}\right)} \bullet u_{i}\right] / \sum_{i} u_{k\left(u_{i}\right)}
$$

After get $\mathrm{U}_{\mathrm{k}} *$ and multiply with scaling factor, can get the actual control volume of controlled object.

Through the design of fuzzy process, fuzzy reasoning, clearness, a complete fuzzy controller was constructed successfully. In order to save the system resources, the look-up table method was used. Concretely, use the possible values of $\Delta \mathrm{T} / \Delta \mathrm{T}$ and $\Delta \mathrm{u} / \Delta \mathrm{T}$ to calculate the corresponding output $\mathrm{Uk}^{*}$, generated a fuzzy lookup table which would be wrote to the ROM of single chip.

\section{EXPERIMENTAL CONCLUSION}

Take $12 \mathrm{~V} / 10$ Ah Lead battery as experimental object, its biggest charging current is $3.5 \mathrm{~A}$, three phase control model and fuzzy control intelligent dynamic charging mode was used respectively to do charging test, processing with charging, charging current was recorded discontinuously, according to the records data got the two kinds of the charging current change curves, as shown in figure 8 .

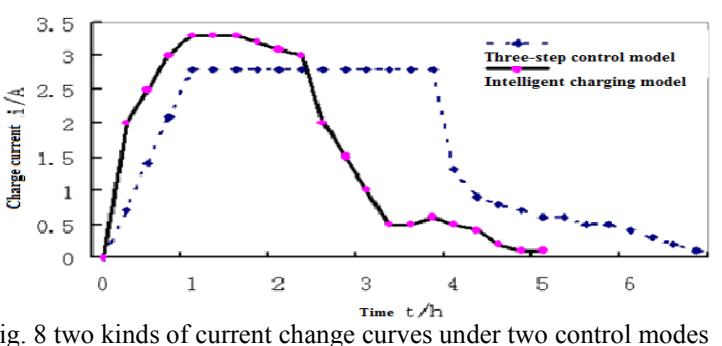

Fig. 8 two kinds of current change curves under two control modes

The above curves showed that: (1) the fuzzy control intelligent charging model charge quicker than three-step control model about 2 hours. (2) Under the fuzzy control charging model the maximum charge current will be close to $3.5 \mathrm{~A}$, this shows fuzzy control and intelligent dynamic charging model can identify the max acceptable charge current automatically. (3) During charging, the battery's temperature was monitored, temperature rise under fuzzy control mode less than three-step control model. So conclusion: intelligent dynamic charging system based on the fuzzy control can realize real-time changes according to battery's acceptable current, improved charging efficiency and achieved a high efficiency, quick and safe charging purpose.

The following projects funded the paper: Agricultural University of Hebei fund support project (Fs20100505); Science and Technology hall of Hebei province S\&T plan support project (1212144); Scientific research and development plan of Baoding support project (12ZN020).

\section{REFERENCES}

[1] Qiu shu-bo. Lead-acid battery automatic charge and discharge controller design [J]. Electronic technology applications, 2001, 27 (6) : 32-33

[2] Gaotian, Jingzhan-rong, Yang yan .Study on Battery pack fast charging fuzzy control technology [J]. Computer simulation. 2006. (10) : 236-238.

[3] XieJiJian. LiuChengPing. Fuzzy mathematics method and application [M].Wuhan: Huazhong science and technology university press. 2005.

[4] ZhangXing, YangWeiMin, LiGangYuan. Intelligent battery charging device [J]. Shanghai University of Science and Technology Journal , 2004 (4) : 381-384

[5] li xubao, ZhaoYongJian. Power electronics device and its application [M]. Beijing: mechanical industry press, 1996. 